SOCIEDAD CHILENA DE NEUMOLOGÍA PEDIÁTRICA
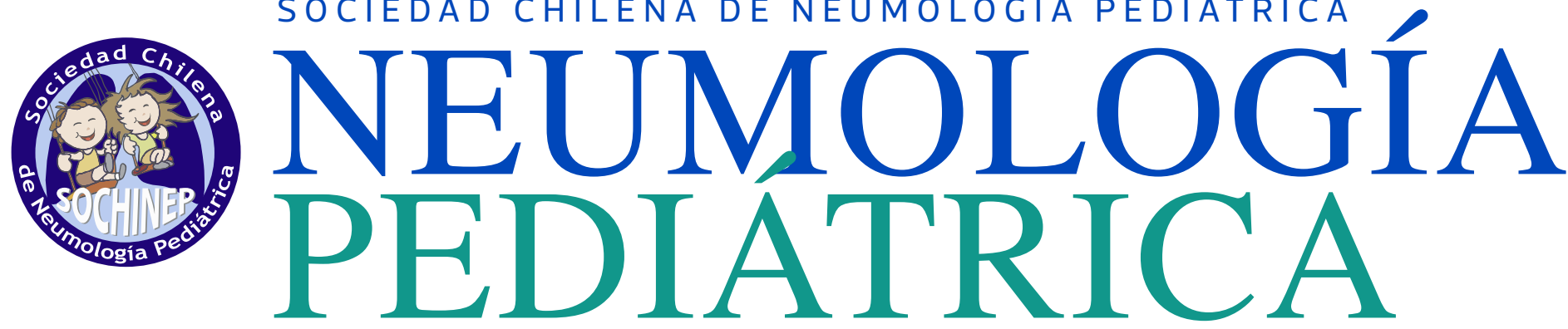

Órgano oficial de difusión de la Sociedad Chilena de Neumología Pediátrica (SOCHINEP) y de la Sociedad Latinoamericana de Neumología Pediátrica (SOLANEP)
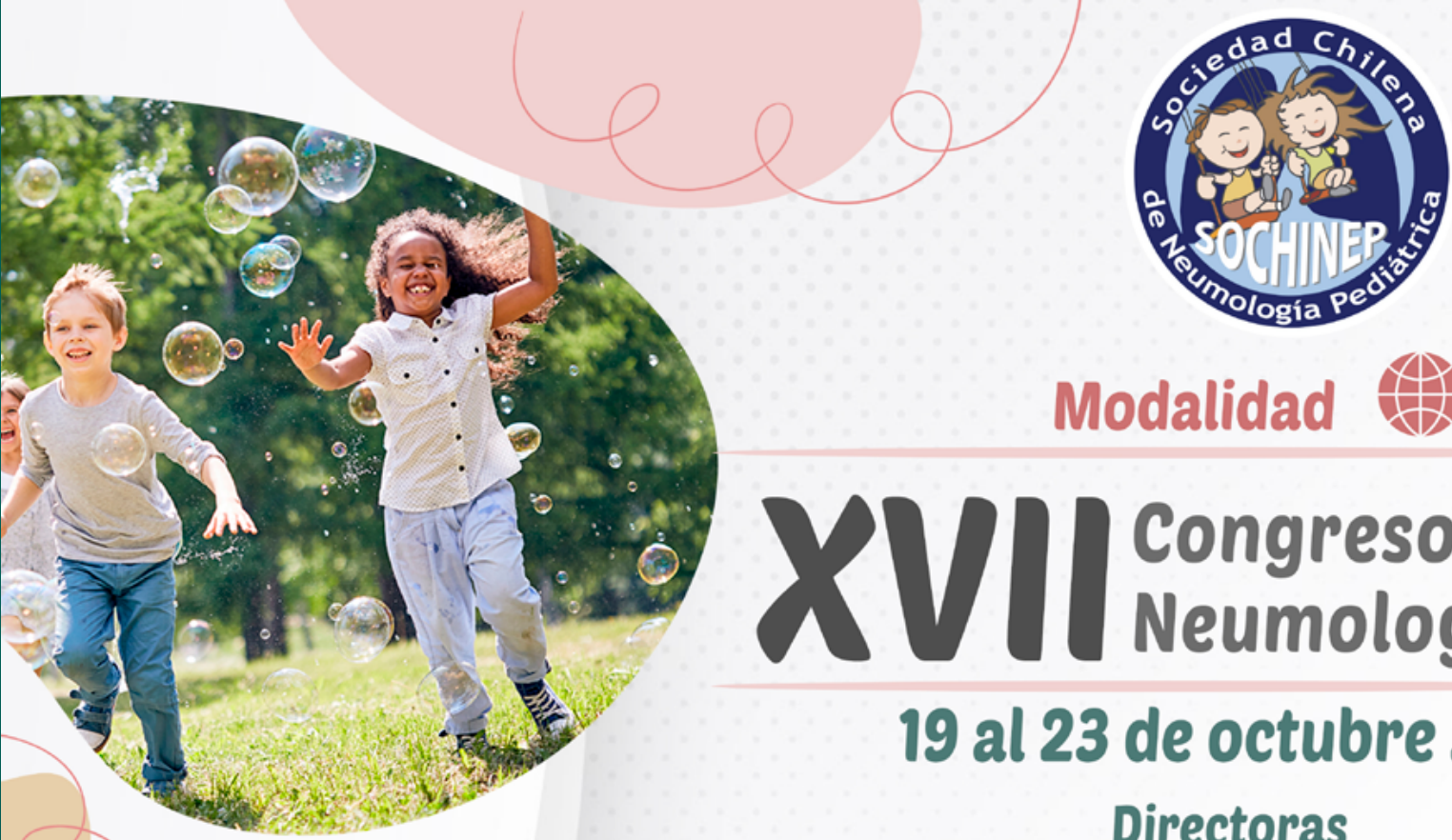

Modalidad nline

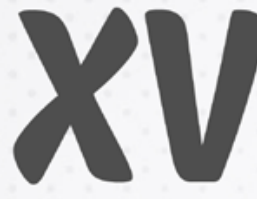

Congreso Chileno de Neumología Pediátrica

19 al 23 de octubre 2021

Directoras

Dra. Ana María Herrera y Dra. Soledad Montes

Resúmenes trabajos libres del

XVII Congreso de la Sociedad Chilena de Neumología Pediátrica

OCTUBRE 2021 

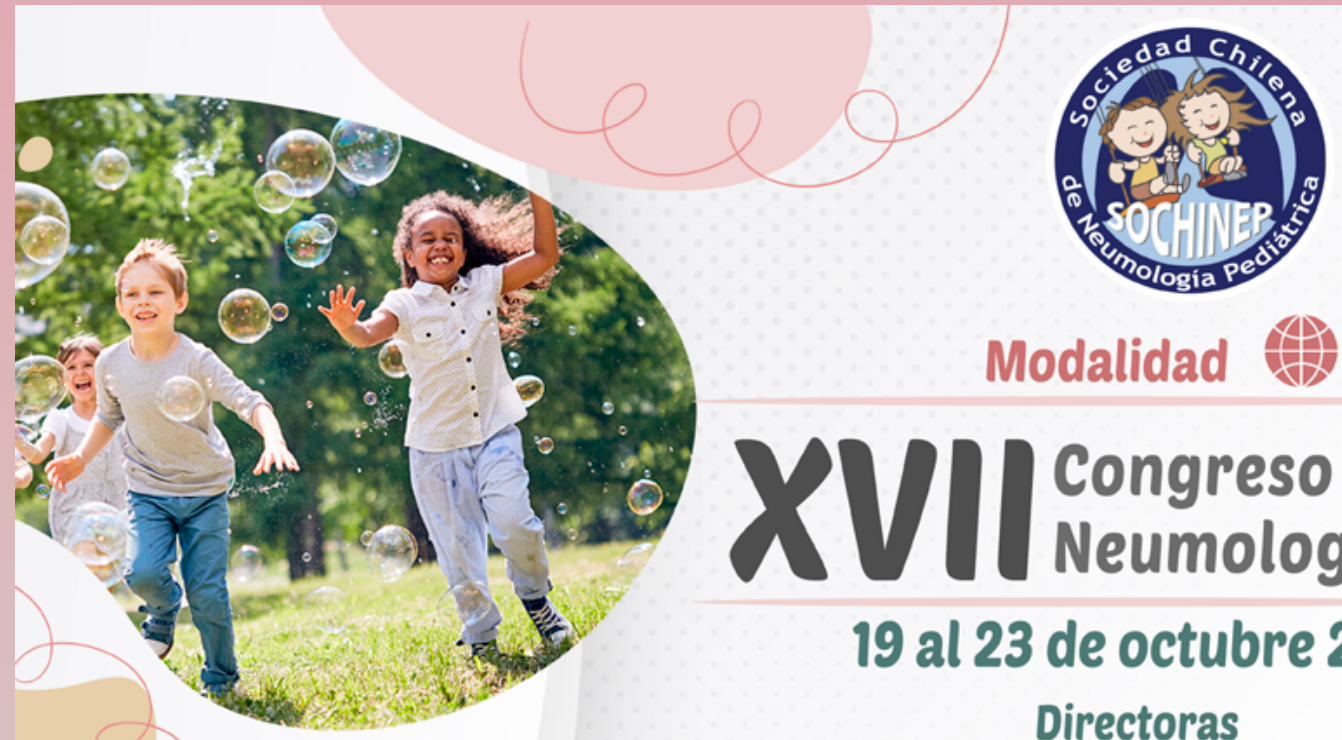

Modalidad \&nline

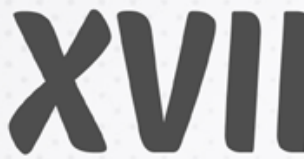

Congreso Chileno de Neumología Pediátrica

19 al 23 de octubre 2021

Directoras

Dra. Ana María Herrera y Dra. Soledad Montes

TEMAS PRINCIPALES

- ASMA

- FUNCIÓN PULMONAR

- FIBRosis Quística

- TÉCNICA INHALATORIA

- TUBERCULOSIS

- RAYOS

- RESPIRACIÓN DISFUNCIONAL

- BRONQUIECTASIAS NO FQ

- MICROBIOMA

- bRONCOSCOPÍa

- teCNOlogías digitales

\section{VALORES \\ antes del 19 de septiembre}

Médico socio al día

25.000

Otro profesional socio al día

Medico no socio

20.000

Otro profesional no socio

40.000

Becados

Internos

Extranjeros

Jubilados

35.000

gratis

10.000

30 dólares

10.000

\section{VALORES}

luego del 19 de septiembre

Médico socio al día

50.000

Otro profesional socio al día

Medico no socio

Otro profesional no socio

Becados

Internos

Extranjeros

Jubilados
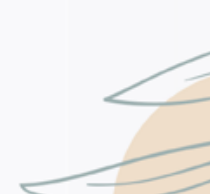

40.000

60.000

50.000

gratis

10.000

10.000

60 dólares

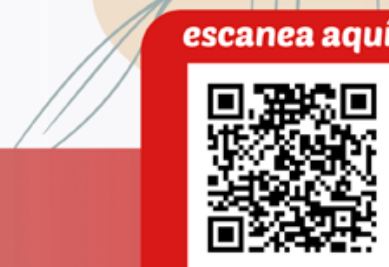




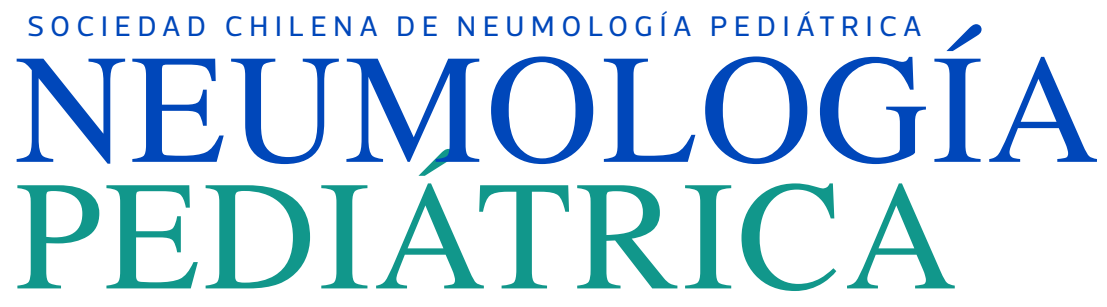

Órgano oficial de difusión de la Sociedad Chilena de Neumología Pediátrica (SOCHINEP) y de la Sociedad Latinoamericana de Neumología Pediátrica (SOLANEP) 


\title{
NEUMOLOGÍA PEDIATRICA
}

\author{
EDITOR RESPONSABLE \\ Dra. Marcela Linares \\ Pediatra Especialista en Enfermedades Respiratorias, \\ Clínica INDISA. \\ Santiago, Chile.
}

\section{COMITÉ EDITORIAL}

\section{Dra. María Lina Boza \\ Pediatra Especialista en \\ Enfermedades Respiratorias. Jefe Unidad Respiratorio Infantil Hospital San Borja-Arriarán. Profesor Adjunto de Pediatría Universidad de Chile. Santiago, Chile.}

\section{Dra. Solange Caussade}

Sección Función pulmonar. Pediatra Especialista en Enfermedades Respiratorias. Profesor Asociado Adjunto, Facultad de Medicina Pontificia Universidad Católica de Chile. Hospital Dr. Sótero del Río. Santiago, Chile.

\section{Dr. Alejandro Colom}

Médico Neumólogo Pediatra del Hospital de Niños R. Gutiérrez. Docente adscrito de neumonología, Facultad de medicina de la U.B.A. Investigador del CODEl del Ministerio de Salud de CABA. Buenos Aires, Argentina.

\section{Dr. Eduardo Lentini}

Pediatra Neumonólogo.

Especialista en Terapia Intensiva infantil. Ex jefe de Servicio de Neumonología y Centro de Fibrosis Quística. Hospital Pediátrico H.J. Notti. Mendoza, Argentina.

\section{Dr. Julio Maggiolo}

Sección Casos clínicos.

Pediatra Especialista en

Enfermedades Respiratorias

Hospital Dr. Exequiel González Cortés

Santiago, Chile.

\section{Dr. Víctor Monreal}

Pediatra Supervisor de la Unidad

del Paciente Crítico Pediátrico,

Clínica INDISA.

Profesor Asistente, Escuela de Medicina

Universidad Andrés Bello Magister en Salud

Pública,

mención Gestión de Salud.

Santiago, Chile.

\section{Klgo. Claudio Olmos \\ Magister en Salud Pública. \\ PhD en Investigación Biomedica \\ y Salud Pública. \\ Escuela de Medicina, \\ Universidad Andrés Bello. \\ Unidad de Investigación Clínica, \\ Clínica INDISA. \\ Santiago, Chile.}

\section{Dra. María Angélica Palomino \\ Sección como leer y generar publicaciones científicas. \\ Pediatra Especialista en \\ Enfermedades Respiratorias. \\ Porfesor Titular de Pediatría, \\ Universidad de Chile. \\ Clínica Las Condes y Hospital \\ Roberto del Río. \\ Santiago, Chile.}

Klgo. Iván Rodríguez Núñez

Magíster en Fisiología Humana, PhD en Ciencias Médicas (UFRO) Departamento de Kinesiología, Facultad de Medicina, Universidad de Concepción, Concepción, Chile.

\section{Dra. Lilian Rubilar}

Sección Casos clínicos. Pediatra Especialista en Enfermedades Respiratorias Hospital Dr. Exequiel González Cortés. Santiago, Chile.

\section{Luis Enrique Vega -Briceño \\ Pediatra Broncopulmonar, Clínica Alemana de Santiago. Profesor Asociado de Pediatría, Universidad del Desarrollo. Asesor Médico GSK Chile.}


SOCIEDAD CHILENA DE NEUMOLOGÍA PEDIÁTRICA
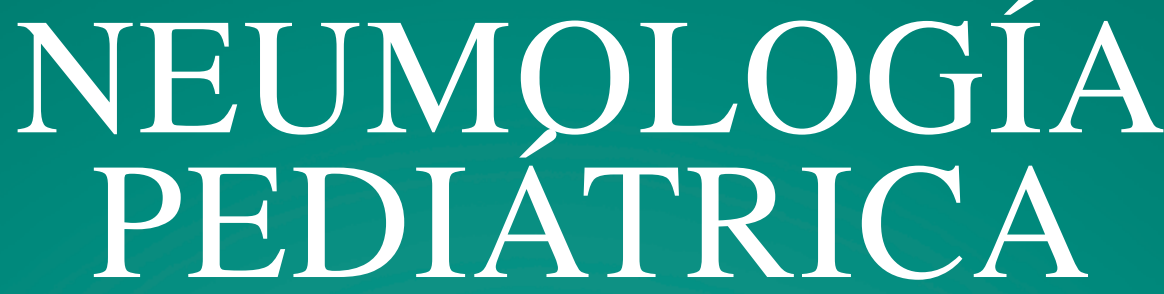

VOLUMEN 16 | SUPLEMENTO 1 | Páginas $1 \mathrm{~s}-10 \mathrm{~s}$

CONTENIDO

Resúmenes trabajos libres del XVII Congreso de la Sociedad Chilena de Neumología Pediátrica OCTUBRE 2021 


\section{COVID 19}

\section{CURSO E-LEARNING "DESAFÍOS DE LA PANDEMIA COVID-19 EN PEDIATRÍA". CARACTERIZACIÓN Y RELACIÓN CON LOS RE- SULTADOS DE APRENDIZAJE Y GRADO DE SATISFACCIÓN}

Daniel Zenteno ', Carlos Flores ${ }^{2}$, José Perillán ${ }^{3,4,5}$, María Ester Pizarro ${ }^{6}$, Gema Perez ${ }^{5,7,8}$, Francisco Prado ${ }^{4,9}$, Víctor Monreal ${ }^{7}$, Ida Concha ${ }^{8}$, Marcela Concha ${ }^{6}$, Roberto Vera ${ }^{4}$, Gerardo Torres ' , Fidel Avendaño ${ }^{4}$, Verónica Cox ${ }^{1}$, Alejandra Zamorano ${ }^{2}$, María Teresa Solís ${ }^{12}$, Ana María Herrera ${ }^{13}$

1.- Universidad de Concepción. Hospital Guillermo Grant Benavente.

2.- Universidad Pedro de Valdivia. Hospital Provincial de Ovalle.

3.- Hospital San Juan de Dios, Hospital el Carmen.

4.- Universidad de Chile

5. - Universidad Finis Terrae.

\author{
6.- Pontificia Universidad Católica de Chile. \\ 7.- Hospital Exequiel González Cortés. \\ 8.- Universidad de San Sebastián. \\ 9.- Hospital Clínico San Borja Arriarán. \\ 10.- Universidad Andrés Bello.
}

\author{
11.- Clínica INDISA \\ 12 - Instituto de Ciencias de la Salud \\ Universidad de O'Higgins, Rancagua \\ 13.- Clínica Santa María.
}

Introducción: Frente a la pandemia del CoVID-19, resulta fundamental establecer estrategias, manteniendo distanciamiento social, que permitan educar a profesionales de la salud sobre aspectos relacionados con SARS-CoV-2. La Sociedad Chilena de Neumología Pediátrica creó un E-learnig de contingencia de acceso libre. Objetivo: Conocer el perfil de participantes al curso "Desafíos de la pandemia CoVID-19 en Pediatría", evaluando su relación con los resultados y grado de satisfacción. Métodos: Estudio transversal. Muestreo por conveniencia de todos los inscritos en este curso, entre mayo 2020 y julio 2020. Se grabaron 12 clases por especialistas con representación académica de Chile. Se realizó prueba final y una encuesta de satisfacción, con puntaje de 1 a 7. Se realizó análisis descriptivo e inferencial, evaluando asociación entre clasificación final del curso, profesión y zona geográfica de los participantes con test de Kruskal Wallis, significancia estadística $p<0,05$. Aprobado por comité ética. Resultados: Participaron 2541 alumnos, 73\% mujeres. Mediana de edad 32,7 años. 90,7\% de Chile, de estos 63,2\% de regiones. Procedencia extranjera destacó Bolivia(2,9\%) y Ecuador (2,5\%). De los que realizaron la prueba, el $98,6 \%$ aprobó. Existió diferencia entre notas según profesión, Médicos-Kinesiólogos ( $p=0.025$ ) y Médicos-Enfermeras ( $p=0.002$ ); y según procedencia, RM-Otras regiones $(p=0.041)$, RM-Internacional $(p<0,001)$ y Otras regiones-Internacional $(p<0,001)$. La evaluación de contenidos ponderó 6,6 y la accesibilidad 6,8 . El $98 \%$ contestó que el curso cumplió sus expectativas. Conclusión: Se inscribió un gran número de alumnos de Chile y Latinoamérica. Más del $98 \%$ aprobó la prueba final y refirió un alto nivel de satisfacción. Sugerimos emplear estrategias similares en situaciones de catástrofes sanitarias.

\section{CAMBIOS IMAGENOLÓGICOS EN PACIENTES DIAGNOSTICADOS CON COVID-19 Y SÍNDROME INFLAMATORIO MULTISISTÉ- MICO PEDIÁTRICO ASOCIADO A SARS-COV-2. EXPERIENCIA EN EL HOSPITAL DR. FELIPE GUEVARA ROJAS}

\section{Mario Gómez Arredondo \\ Hospital Dr. Felipe Guevara Rojas, El Tigre, estado Anzoátegui, Venezuela.}

Introducción: Desde finales del 2019 con la aparición de SARS-CoV-2 y su posterior declaración de pandemia de la COVID-19, cada vez son más los reportes de infecciones en pacientes pediátricos en diversos países, así como la aparición del Síndrome Inflamatorio Multisistémico Pediátrico asociado al SARS-CoV-2 como su complicación máxima. Objetivo: Determinar los cambios imagenológicos en los pacientes pediátricos diagnosticados con COVID-19 y con Síndrome Inflamatorio Multisistémico Pediátrico asociado a SARS-CoV-2 (SIMSP-asociado a SARS-CoV-2). Métodos: Se estudió a los pacientes con sintomatología de COVID-19 y de Síndrome Inflamatorio Multisistémico Pediátrico asociado a COVID-19 desde Agosto de 2020 hasta Julio de 2021 en el Hospital centinela Dr. Felipe Guevara Rojas la ciudad de El Tigre, estado Anzoátegui, Venezuela. Resultados: De 110 pacientes estudiados, 65 pacientes se diagnosticó
COVID-19 y 45 fueron diagnosticados con SIMSP asociado a SARSCoV-2; los cambios en Rayos X en el grupo con COVID-19 fue de $46 \%$ con imágenes de condensación unilateral en mayor medida, en el grupo de SIMSP asociado a SARS-CoV-2 los cambios fue en $55 \%$ con la presencia de condensaciones bilaterales con cambios bronquiales principalmente; en el $100 \%$ de los pacientes de ambos grupos se presentaron cambios a nivel de tomografía donde predominó la imagen en vidrio despulido. Conclusión: Los cambios imagenológicos pueden evidenciarse aun en pacientes asintomáticos, a pesar que en Rayos $X$ no se evidenciaron cambios en la mayoría de los pacientes, al realizar estudio tomográficos se logró observar en pacientes asintomáticos y sin cambios previos en Rayos X.

\section{CARACTERIZACIÓN EPIDEMIOLÓCICA DE PACIENTES CON COVID-19 EN EL SERVICIO DE URGENCIA PEDIÁTRICO DE UN HOSPITAL DE ALTA COMPLEJIDAD}

\section{Mireya Méndez, R Madrid, P Olivares, K Loayza , D Wong , A Vanegas , S González , X Guastavino}

Unidad Broncopulmonar Infantil CASRZ, Santiago, Chile.

Introducción: En edad pediátrica, el COVID-19 se ha comportado de una forma menos agresiva, con menos casos y menor mortalidad que en la edad adulta. A nivel nacional, se han notificado 246.689 casos, mediana de edad 11 años. 32,1\% adolescentes, con aumento del 160\% en el 2021 . Objetivo: Describir características clínicas de niños con COVID-19 atendidos en la Unidad de Emergencia Pediátrica del Complejo Asistencial Dr. Sótero del Río (CASR). Metodología: Estudio observacional, retrospecti- vo, aprobado por Comité de Etica CASR. En base a registros de resultados de PCR Sars-Cov2, entre marzo 2020 y junio 2021; se seleccionaron los pacientes con resultado positivo. Se registró variables demográficas, clínicas e imagenológicas. Se analizó 2 períodos (marzo-diciembre 2020/ enero- marzo 2021. Resultados: Se estudió 437 casos, mediana edad 4,85 años (12 días-19 años). Mujeres 53,5\%. Manifestaciones clínicas más frecuentes: síntomas respiratorios altos $(60 \%)$, gastrointestinales 
(50,1\%). Hospitalizados 10,4\% (58/437), estadía promedio 10,45 días, Ingreso UPC 4,57\%, de ellos 70\%(14/20) obesos. Imágenes 16,4\%(Rx. tórax 48/TAC tórax 24). Al comparar 2020 vs 2021 hubo 203 casos vs 234, mediana edad aumento de 3,1 a 5,8 años, hospitalizados $15(7,8 \%)$ a $43(11 \%)$, aumento casos graves de 2,9\% a 10,6\%, oxígeno 3 a 13\%, VMNI 1,48 a
$6,41 \%$, VMI 0,5 a 2,14\% CNAF 0.99 a 2,14\%. Se reportó 2 casos de PIMS, 1 fallecido 2020, 2 el 2021. Conclusión: Si bien el número de casos en niños es escaso, se observó un aumento el año 2021, con mayor hospitalización y gravedad. La obesidad se asoció a mayor severidad.

\section{CASOS CLÍNICOS}

\section{NÓDULOS PULMONARES COMO MANIFESTACIÓN PULMONAR INFLAMATORIA DE LA ENFERMEDAD DE KAWASA- KI (EK), UN HALLAZGO POCO CONOCIDO}

Taly Saul Arenberg, Pía Escobar Adaros, Juana María Zamorano Riquelme, Mauricio Contreras Gambra

Universidad de los Andes - Clínica Santa María Santiago, Chile.

Introducción: La EK como vasculitis sistémica de vaso mediano genera alteraciones coronarias en fase aguda, sin embargo, los vasos pulmonares no se afectan en igual intensidad. Secundario al compromiso vascular se ha descrito afección pulmonar nodular en imágenes. Se presenta un caso que ejemplifica este hallazgo respiratorio imagenológico. Caso Clínico: lactante previamente sano, hospitalizado por síndrome febril de 5 días de evolución, exantema máculo-papular, trombocitosis e infección respiratoria viral reciente. Evaluado por infectología se describe además BCCitis, labios rojos y resecos, auscultación pulmonar normal, parámetros inflamatorios elevados (PCR hasta $144 \mathrm{mg} / \mathrm{dL}$ ), dímero D 2890, panel viral respiratorio negativo. Se sospecha PIMS versus Enfermedad de Kawasaki. PCR y serología COVID19 negativos. En estudio radiológico destaca engrosamiento intersticial peribronquial central bilateral y opacidades parenquimatosas parcialmente confluentes. Dado posibilidad de EK incompleto asociado a neumonía se solicita ecocardiograma que confirma dilatación de arterias coronarias de forma difusa con aneurisma gigante de descendente anterior y sospecha de trombo intra-aneurisma. Recibe gammaglobulina endovenosa, y aspirina en dosis anti-inflamatoria. Dado pandemia recibe empíricamente metilprednisolona. Por sospecha de trombo inicia anticoagulante y clopidogrel y se evalúa con tomografía evidenciando nódulos pulmonares persistiendo asintomático respiratorio. Conclusión: Las manifestaciones pulmonares de EK son poco frecuentes. Se describe compromiso pulmonar nodular con signo de halo en tomografías, pudiendo variar desde infiltrados micronodulares hasta nódulos inflamatorios de mayor tamaño. Éstos sugieren proliferación capilar y angiogénesis activa como parte del proceso inflamatorio que ocurre en la EK. Su reconocimiento puede permitir una observación cautelosa de estas lesiones hasta la resolución espontánea.

\section{ASPIRACIÓN DE CARBÓN ACTIVADA, UNA RARA COMPLICACIÓN}

Daniela García Obreque, Anwar Gutiérrez Silva, Francisca Castro Zamora

Hospital Padre Hurtado Santiago, Chile.

Introducción: El carbón activado es una de las sustancias más utilizadas en el manejo de intoxicación aguda. Pese a que no se absorbe por el organismo puede generar complicaciones de gravedad como la aspiración de éste, siendo un evento infrecuente con una incidencia aproximada de $1,6 \%$, pero potencialmente fatal. El manejo de la aspiración de carbón activado no está del todo consensuado, por lo que se presenta en caso clínico de aspiración de carbón activado en un adolescente de 17 años tras intoxicación intencional por carbamazepina, quien presentó insuficiencia respiratoria aguda tras administración del carbón. Discusión: En la actualidad existe controversias en el manejo de la aspiración de carbón activa- do, siendo el lavado bronqueo-alveolar un método invasivo con escasa evidencia que lo avale. Cabe destacar que la prevención de las intoxicaciones, como el correcto uso del carbón activado ante los distintos escenarios clínicos que se presentan como es el compromiso de conciencia, disminuirían los eventos de aspiración. Conclusión: El manejo de la aspiración por carbón activado es disímil según el centro donde se produzca, requiriendo mayor evidencia para una recomendación universal, siendo plausible considerar la protección de vía aérea antes de su uso en casos de alteraciones del sensorio.

\section{TUBERCULOSIS MILIAR (TM) COMO CAUSA DE DISTRÉS RESPIRATORIO AGUDO SEVERO EN PEDIATRÍA. DEBUT CRÍTICO DE UNA ENFERMEDAD OLVIDADA}

Fabiola Aguila Aguayo, Evelyn Neira Torres, Pía Escobar Adaros, Javiera Kreft Vega, María Carolina Cruz Barros, Natalie Lara Aguilera

Hospital Roberto Del Río Santiago, Chile.

Introducción: La TM, forma grave de presentación, es causada por diseminación hematógena del bacilo. Es más frecuente en lactantes, niños pequeños, ancianos e inmunosuprimidos. Se presenta un caso de TM excepcional, con debut crítico en adolescente inmunocompetente. Caso Clínico: Mujer haitiana de 14 años, en Chile hace 5 años con historia de 1 mes de tos y fiebre por 2 semanas. Ingresa a urgencia febril, taquicárdi$\mathrm{ca}$, desaturando con dificultad respiratoria leve, y auscultación pulmonar con crépitos bilaterales. Presenta deterioro respiratorio brusco a pesar de manejo de soporte habitual requiriendo intubación urgente y apoyo vasoactivo. Radiología confirma neumonía intersticial difusa con patrón micronodular y derrame pleural izquierdo no complicado. Se inician antibióticos empíricos, y antituberculosos ante sospecha activa de TM. Se solicita estudio de liquido pleural, aspirado traqueal y gástrico, y a las 24hrs lavado broncoalveolar todos con GeneXpert Mycobacterium tuberculosis (MTB) positivo. Estudio de punción lumbar normal negativo. Dado mayor compromiso hemodinámico e hipoxemia severa a pesar de apoyo 
ventilatorio intensivo se modifica vía de tratamiento antituberculoso a endovenoso y se inician corticoides sistémicos posterior a lo cual mejora lenta y paulatinamente la falla respiratoria aguda. Conclusión: Hemos enfrentado aumento de casos de TB miliar en adolescentes, presentación severa y de alta mortalidad sin tratamiento. En inmunocompetentes la incidencia es menor al $2 \%$ siendo el caso descrito muy excepcional. En contexto de retrasos en la vacunación y probable subdiagnóstico en población adulta en pandemia es de esperar un aumento de su incidencia, debiendo anticiparnos para lograr un diagnóstico precoz.

\section{SÍNDROME DE HEINER, REPORTE DE UN CASO}

María Luisa Espinoza Ovalle, Javier Cepeda Soto, Gema Pérez Alarcón

Hospital Exequiel González Cortés Santiago, Chile.

Introducción: El síndrome de Heiner o Hipersensibilidad a la proteína de leche de vaca constituye causa infrecuente de Hemosiderosis pulmonar. Caso Clínico: RNT 37 semanas, sin antecedentes perinatales. Al mes presenta apnea que requiere estimulación vigorosa. Ingresa a urgencia en malas condiciones generales, hipoactiva, polipneica, con sangre en boca. Por compromiso hemodinámico se intuba, sangre fresca por tubo. Evoluciona con distrés respiratorio y sangrado por tubo endotraqueal. Conectada a Ventilación Mecánica invasiva (VMI) por 3 días. Radiografía de tórax muestra compromiso bilateral. Se realiza Lavado Broncoalveolar a los 4 días: anatomía normal, sin sangrado activo, Cultivo corriente y hongos, Citomegalovirus y Pneumocistis Jirovecii negativos. Se da de alta con diagnóstico de Hemosiderosis Pulmonar. Por sospecha de Alergia a la proteína de Leche de Vaca se indica formula extensamente hidrolizada más lactancia materna. Es dada de alta a los 8 días. Reingresa a los 10 días por hemoptisis masiva, cursando shock hipovolémico. Se intuba, maneja con VMI por 1 mes, recibe pulso de metilprednisolona. Estudio inmunológico con anticuerpos antinucleares, antiDNA, C-ANCA, P-ANCA, ANCA atípico, antitransglutaminasa, antiendomisio, anticardiolipinas, Precipitinas/lgG para APLV negativos. Estudio de coagulación normal. Endoscospía digestiva alta: Gastropatía erosiva corporo-antral, ulcera gástrica. En ambas hospitalizaciones con anemia importante que requiere transfusión. Se diagnostica Hemosiderosis pulmonar, probable Sindrome de Heiner. Se mantiene en tratamiento prolongado con corticoides sistémicos (ya suspendidos) y corticoides inhalados. Actualmente 2 años 9 meses, sin nuevos episodios. Conclusión: Síndrome de Heiner debe sospecharse en lactantes pequeños con hemorragia alveolar e hipersensibilidad a la proteína de leche de vaca.

\section{HIPERPLASIA DE CÉLULAS NEUROENDOCRINAS. PRESENTACIÓN DE 7 CASOS}

\section{Julio Maggiolo Massone, Lilian Rubilar Olivares}

Hospital Exequiel González Cortés Santiago, Chile.

Introducción: La hiperplasia de células neuroendocrinas (HCNE) es una enfermedad pulmonar intersticial (EPI) propia del lactante. Objetivo: presentar 7 pacientes con HCNE, en los últimos 20 años. Casos Clínicos: 7 casos, 6 niños y 1 niña. Edad de inicio de sintomatología: desde período de RN hasta 5 meses, edad al diagnóstico: 1 a 8 meses (latencia 0 a 7 meses), edad actual: 1 a 20 años. Todos presentaron retracciones y polipnea, que fue cediendo desde los 10 meses de edad. Radiografía de tórax: hiperinsuflación y tomografía computada de tórax: vidrio esmerilado en los lóbulos medio y língula, atrapamiento aéreo. Se les practicó a dos pacientes espirometría que resultaron: patrón obstructivo reversible. Ninguno llegó a biopsia pulmonar. Tampoco requirieron corticoides sistémicos prolongados. Cinco necesitaron 02 mediante naricera, desde 15 días hasta 20 meses, suspendido con oximetría nocturna normal, tres presentaron desnutrición. Dos pacientes evolucionaron con un síndrome bronquial obstructivo (SBO) por VRS, hospitalizados, requirieron como terapia salbutamol MDI, prednisona y 02 . Hasta la fecha todos se encuentran vivos y dos presentan asma en tratamiento. Comentarios: el diagnóstico fue hecho por la presentación clínica, imagenología y su favorable evolución, no solicitándoseles biopsia pulmonar, lo que la diferencia de otras modalidades de EPI. La desnutrición se debe considerar como evolución no favorable, debiendo estar atentos al aporte de 02. Cabe destacar que posteriormente pueden manifestar hiperreactividad bronquial. La HCNE se debe considerar en el diagnóstico diferencial del SBO y de otras EPI como glicogenosis pulmonar y mutaciones de las proteínas del surfactante.

\section{GLICOGENOSIS PULMONAR: REPORTE DE UN CASO}

María Luisa Espinoza Ovalle, Javier Cepeda Soto, Daniel Rojo Vera, Iván Mendoza González, Lilian Rubilar Olivares, Julio Maggiolo Massone Hospital Exequiel González Cortés Santiago, Chile.

Introducción: La glicogenosis pulmonar (GP) en una enfermedad pulmonar intersticial (EPI) propia del lactante. Caso Clínico: Paciente sexo masculino, padres haitianos. Embarazo controlado, parto prematuro a las 29 semanas. Reanimado con bolsa mascarilla. Evoluciona con síndrome de distrés respiratorio, requiere ventilación mecánica invasiva (VMI) por 13 horas, no recibe surfactante. Tras extubación, aporte de oxígeno (02) en incubadora. Persiste taquipneico, con retracciones subcostales. Radiografía de tórax muestra imágenes intersticiales bilaterales simétricas, persistentes. Evaluado por broncopulmonar, solicita estudio: descartados agentes oportunistas (P. jiroveci, citomegalovirus (CMV)), Lavado Broncoalveolar (LBA): PCR VEB, Virus Herpes 1 y 2, CMV, cultivo corriente, negativos. PCR SARS COV2 (2), PCR virus respiratorios, PCR Mycobacterias, ELISPOT TBC negativos. Ecocardiograma y ecografía cerebral normales. Tomografía computada (TC) de tórax: imágenes sugerentes de neumonía intersticial. Se realiza nuevo LBA, estudio anatomopatológico revela PAS (+) $18 \%$, sugerente de proteinosis alveolar. Biopsia pulmonar mediante Videotorascopía informa glicogenosis pulmonar, focos incompletos y en parche de displasia alveolocapilar y simplificación alveolar. Se solici- 
ta estudio genético, pendiente resultado. 02 suspendido a los 70 días. A los 4 meses presenta neumonía VRS grave, con requerimientos prolongados de VMI (18 días). Recibe pulso de metilprednisolona y prednisona de mantención, siendo dado de alta sin 02. El diagnóstico de displasia alveolocapilar es dudoso, dada buena evolución y respuesta a corticoides.
Conclusión: Se presenta caso de paciente con displasia broncopulmonar, que evoluciona con taquipnea en el cual estudio confirma GP. La clínica, estudio imageneológico, biopsia pulmonar y estudio genético permiten realizar el diagnóstico diferencial de las EPI del lactante.

\title{
REPORTE DE CASO: AGENESIA PULMONAR EN HOSPITAL DE PUERTO MONTT (HPM)
}

Constanza Herrera Torres, Marcela Villarroel Hernández, Juan Zúñiga Camblor, Fernando Iñiguez Osmer

Hospital Puerto Montt. Santiago, Chile.

Introducción: Las malformaciones congénitas de vía aérea incluyen un amplio espectro de patologías poco frecuentes, incluyendo la agenesia pulmonar, que debe ser considerada dentro del diagnóstico diferencial del recién nacido $(\mathrm{RN})$ con distrés respiratorio. La severidad del cuadro es variable y el pronóstico depende de la presencia de otras malformaciones asociadas. Objetivo: describir caso clínico de agenesia pulmonar en unidad de Neonatología del HPM. Desarrollo: RN pretérmino, 35 semanas, pequeño para la edad gestacional, sospecha antenatal de hernia diafragmática y atresia duodenal. Nace por cesárea de urgencia (preeclampsia severa), APGAR 8-8, apoyo inicial con CPAP +5 en el periodo de RN inmediato, evolucionando sin requerimientos de apoyo ventilatorio ni oxígeno adicional. Por sospecha de atresia duodenal se realiza laparotomía exploradora al sexto día de vida, confirmando malformación. Se realiza anastomosis duodenoduodenal sin incidentes. Desde el punto de vista respiratorio en radiografía de tórax: velamiento de hemitórax izquierdo con desviación de la vía aérea. Ante la sospecha de agenesia pulmonar se completa estudio con TC tórax: ausencia pulmonar izquierda global y rama pulmonar, produciendo desviación del mediastino y silueta cardíaca a izquierda, con sobreexpansión compensatoria pulmonar derecha. Fibrobroncoscopía: tráquea sana sin estenosis, foseta en zona del bronquio fuente izquierdo, resto normal. Evoluciona en buenas condiciones generales. Dado de alta sin requerimientos de oxígeno a los 33 días de vida, con buen incremento ponderal. Se administró vacuna antineumocócica al paciente y antiinfluenza a los contactos. Actualmente en controles periódicos en Hospital Luis Calvo Mackenna por equipo de cirugía de vía aérea.

\section{PROBABLE DISEMINACIÓN DE VACUNA BCG EN LACTANTE INMUNODEFICIENTE}

Lilian Rubilar Olivares, Julio Maggiolo Massone, Selim Abara Elías

Hospital Exequiel González Cortés, Santiago, Chile.

Introducción: La vacunación BGC protege a recién nacidos (RN) contra la tuberculosis (TBC) miliar y meníngea hasta 5 años, aunque reviste peligro de diseminación en RN inmunodeficientes (ID).Caso Clínico: RN término, padres sanos, hospitalizada 11 dias : Neumonía connatal sin germen identificado. Recibe 02, apoyo CPAP. El 04-03-2021 con 5 meses, se hospitaliza por SBO moderado ( $3^{\circ} \mathrm{dia}$ ) -Eutrofia. Cicatriz BCG+. Requiere $\mathrm{VMNI}+02$, panel viral (-), evoluciona a Insuficiencia respiratoria aguda es intubada.TC tórax neumonía multifocal con fibrosis. En $2^{\circ}$ semana se hizo Lavado broncoalveolar : PCR para Mycobacterium complex, P.jiroveci y Rhinovirus positivas. CMV(-), VEB(-). Inicia :rifampicina, isoniacida, etambutol pirazinamida. Tratamiento completo para P. jiroveci. Corticoides sistémicos prolongados. Nuevos exámenes: VIH (-), recuentos lg: bajos. Subpoblaciones linfocitarias: CD4 y CD8(-), presencia de LB(CD19) y NK compatible con Síndrome Inmunodeficiencia Combinada Severa (SCID). PPD: Omm, Quantiferon indeterminado, PCR contenido gástrico + para Mcomplex. TAC cerebro: normal TC pulmonar(2): sin cambios. Estudio hongos(-). Fondo de ojo normal. Pannel INVITAE para ID: muestra escasa. No se pudo serotipificar cepa de M complex. Evoluciona con gravedad extrema, difícil de ventilar aún con traqueostomía (05-04-21). Postulada para trasplante médula ósea. Fallece 10-04-21. Diagnósticos: Insuficiencia respiratoria refractaria/Neumonía grave multifocal Mycobacterium complex-Pjirovecci /SCID/ Probable diseminación BCG. Padres sin TBC. Discusión: La diseminación BCG es desde 0,06 -1.56/100000 vacunados VIH-, causa mortalidad frecuente en ID $1^{\circ}$. En esta lactante no fue posible demostrar diseminación BCG aunque es altamente probable que así ocurriera ante el cuadro clínico presentado.

\section{FIBROSIS QUISTIICA}

\section{MONITORIZACIÓN DE NIVELES DE VANCOMICINA Y AMIKACINA EN PACIENTES CON FIBROSIS QUISTICA: EXPE- RIENCIA DE PACIENTES HOSPITALIZADOS EN HOSPITAL EXEQUIEL GONZÁLEZ CORTÉS}

\author{
Daniela Figueroa Sánchez, Gema Perez Alarcon, Ricardo Kogan Alterman, Ruben Hernandez Mazurek \\ Hospital Exequiel González Cortés Santiago, Chile.
}

Introducción: La fibrosis quística (FQ), es una enfermedad genética autosómica recesiva. Causada por mutaciones en el gen regulador de la conductancia transmembrana de la fibrosis quística (CFTR) que codifica un canal de cloruro en la membrana apical de las células epiteliales del sistema exocrino. En Chile, tiene una incidencia de 1 en 8.000 a 10.000 recién nacidos vivos. Las exacerbaciones pulmonares infecciosas en pa- cientes con fibrosis quística se asocian a mayor morbimortalidad por lo que su manejo con antimicrobianos como la amikacina y vancomicina es escencial, sin embargo estos presentan cambios farmacocinéticos dificultando su dosificación y generando la necesidad de monitorizar sus niveles plasmáticos, para aumentar eficacia y reducir efectos adversos. Existen pocos estudios en población pediátrica que analicen la monito- 
rización de estos antimicrobianos, particularmente en pacientes con FQ, por lo que este trabajo sirvirá para describir si las dosis indicadas en esta población alcanzan concentraciones plasmáticas terapéuticas. Objetivo: Optimización de dosificación con vancomicina y amikacina en pacientes con fibrosis quística mediante la utilización de niveles plasmáticos. Materiales y método: Este estudio es descriptivo, retrospectivo. Utilizando base de datos con concentraciones plasmáticas de Vancomicina y Amikacina en pacientes pediátricos con diagnóstico de fibrosis quística del Hospital Exequiel González Cortés entre los años 2018-2020.Para vancomicina la monitorización se realizó mediante la determinación de concentraciones basales o valle (Cbasal), que corresponde a la concentración plasmática medida media hora previa a la cuarta dosis que deben estar entre 10-20 $\mu \mathrm{g} / \mathrm{mL}$.Para amikacina la monitorización se realizó con concentración peak (medición tras la segunda dosis y media hora posterior al término de la infusión). Se consideró terapéutico CIM 32. Y nivel valle medido media hra previo a la segunda dosis, considerado normal < 2 $\mu \mathrm{g} / \mathrm{mL}$. Resultados:: Durante 2018 al 2020 se registran 121 niveles plasmáticos valle de Vancomicina y 64 niveles peack de Amikacina. Durante 2020 se registran 16 niveles plasmáticos Valle de Amikacina. En relación a la vancomicina, se observa que los niveles promedios durante $2018 \mathrm{al}$ 2020 prevalecen los niveles en rango terapéutico, seguido por niveles sub terapéutico y luego rangos supra terapéuticos. Por lo que se puede deducir que la dosis inicial $(60 \mathrm{mg} / \mathrm{k}$ fraccionado cada 8 hras) utilizada en paciente FQ es suficiente. En cuanto a la Amikacina se observan los niveles promedios durante 2018 al 2020 donde prevalecen los niveles en rango subterapéutico. Por lo que se puede deducir que la dosis rango inicial 20-30 mg/k utilizada en paciente FQ es insuficiente. El lugar de hospitalización predominante donde tomaron ambos niveles plasmático fue sala básica. Según distribución de sexo de nivel plasmático, el sexo masculino corresponde al $58 \%$ de las tomas de vancomicina y el sexo femenino corresponde al $57.5 \%$ de las tomas de amikacina.

\section{EFECTOS DE LA PANDEMIA COVID19 EN PACIENTES PEDIÁTRICOS CON FIBROSIS QUÍSTICA CONTROLADOS EN HOSPITAL SOTERO DEL RÍO}

Pablo Jorquera P, Pamela Maturana A, Ricardo Madrid H, Dra. Solange Caussade L.

Hospital Sotero del Río, Santiago, Chile.

Introducción: Desde la aparición del primer paciente infectado por SARS Cov 2 en nuestro país el año 2020, se restringió la posibilidad de atención presencial de los pacientes con enfermedades crónicas, incluyendo la fibrosis quística. Objetivo: Comparar la función pulmonar, estado nutricional y exacerbaciones durante el periodo prepandemia y durante la pandemia. Pacientes y método: Aprobado por el comité ético-científico. Estudio descriptivo retrospectivo. Se obtuvo variables clínicas y de laboratorio mediante la revisión de fichas clínicas. Se consideraron pacientes entre 6 y 18 años controlados en Unidad de Broncopulmonar Infantil del Hospital Sótero del Río. Se revisaron sus fichas clínicas durante período pre-pandemia (1 enero 2019 a 31 marzo 2021) y durante la pandemia (1 abril 2020 a 30 junio 2021). Resultados: Se analizaron 7 pacientes con edades entre 11 a 17 años, 4/7 mostraron reducción de CVF y VEF 1, 5/7 mostraron reducción de FEF 25-75. En 3/7 hubo reducción del IMC, sólo en 1/7 aumentaron las hospitalizaciones y número total de exacerbaciones respiratorias. Conclusión: Al igual que lo reportado en literatura internacional se apreció en el periodo de pandemia disminución del número de exacerbaciones y hospitalizaciones, sin embargo esto no se tradujo en beneficios en la función pulmonar.

\section{ENFERMEDADES NEUROMUSCULARES}

\section{CARACTERIZACIÓN CLÍNICA Y FUNCIONAL RESPIRATORIA DE PACIENTES CON DISTROFIA MUSCULAR DE DU- CHENNE (DMD)}

Graciela Roa Silva, Pamela Maturana Aracena, Marie Solange Caussade Larraín , Daniela Ávila Smirnov, María de los Ángeles Beytía Reyes, Beatriz Velásquez Diaz, Carolina Campos Olmedo

Pontificia Universidad Católica de Chile.

Introducción: La DMD es una enfermedad genética recesiva ligada al $X$, cuya incidencia es de 1:3000 hombres nacidos vivos. Se caracteriza por un deterioro progresivo de la fuerza muscular general y respiratoria. Esta última se puede evaluar mediante varias técnicas. Objetivos: describir la evolución clínica y de la función muscular respiratoria de los pacientes con DMD controlados en la Unidad de Respiratorio Infantil del CASR. Sujetos y método: estudio descriptivo retrospectivo basado en revisión de fichas clínicas y exámenes de función respiratoria de pacientes con DMD controlados en nuestra Unidad. Aprobado por Comité de ética SSMSO. Resultados: 21 pacientes, mediana edad 14 años (3,6-23), mediana edad diagnóstico 5,6 años (1,6-10), mediana edad pérdida deambulación 10 años (9-12). En la espirometría se observó pérdida progresiva de la CVF.
La última PIM (presión inspiratoria máxima) medida fue superior a $80 \%$ de la predicha solo en 4 pacientes. El rango de PEF con tos fue entre 230 y $410 \mathrm{~L} / \mathrm{mn}$. Poligrafía con mediana AHI 1,5 (0,2-7,8). Doce pacientes recibieron reclutamiento pulmonar y asistencia de la tos con bolsa de reanimación y 7 usaban VNI nocturna. Conclusión: La vigilancia respiratoria es un componente esencial del cuidado de los pacientes con DMD, ya que el compromiso de la musculatura respiratoria suele ser precoz. Esta evaluación permite seguir la progresión del compromiso respiratorio, tomar decisiones terapéuticas y evaluar respuesta a tratamiento. Es importante tener protocolos de evaluación que permitan una conducta anticipatoria y protocolos de tratamiento multidisciplinario. 


\section{EPIDEMIOLOGÍA CLÍNICA}

DISPLASIA BRONCOPULMONAR EN PREMATUROS MENORES DE 32 SEMANAS: ¿ES EL REQUERIMIENTO DE OXÍGENO A LOS 28 DÍAS DE VIDA UN BUEN PREDICTOR?

\section{Marcela Linares Passerini, Javier Cifuentes Recondo, Rosita Silva Muñoz, Sergio Ambliado Torres}

Clínica INDISA Santiago, Chile.

Introducción: La displasia broncopulmonar (DBP) es la enfermedad pulmonar crónica más frecuente del recién nacido prematuro. El requerimiento de oxígeno (02) por 28 días y a las 36 semanas (DBP36s) son las definiciones más utilizadas. Objetivo: En prematuros menores de 32 semanas (RNP<32) nacidos en una unidad neonatal en Santiago, Chile, entre los años 2012 y 2019: 1.-) evaluar la relación del requerimiento de 02 a los 28 días de vida (DBP28) con DBP36s. 2.-) Describir y conocer la incidencia de DBP36s en RNP<32. Resultados: $725 \mathrm{RN}<32$ s nacieron en la Clínica, 178 fallecieron o se trasladaron a otro centro antes de las 34 semanas, los restantes 547 fueron incluidos en el estudio. La mortalidad fue del $12,4 \%$ (90/725). La incidencia de DBP28 fue $46 \%$ y de DBP36s
37\%. En un análisis de regresión logística los predictores de DBP36s fueron el sexo masculino, OR 2,42 (IC951,24-4,69), peso al nacer, OR 1(IC95 0,99-1), EG, OR 0,75 (IC95 0,57-0,97), APGAR a los 5 min, OR 0,01 (IC95 0,003-0,05), requerimiento de CIPAP/NAF, OR 1,1 (IC95 1,04-1,17) y los días de VMI, OR 1,1 (IC95 1-1,2). El 6,3\% (16/252) con DBP28, no requirió oxigeno por más de 28 días consecutivos y solo el $15 \%$ de los DBP28 no fueron DBP36s. Conclusión: El requerimiento de oxígeno a los 28 días es un muy buen predictor de DBP36s. Los predictores asociados a DBP36s fueron el sexo masculino, peso al nacer, EG, APGAR, requerimiento de presiones en la vía aérea y los días de VMI.

\section{VENTILACIÓN MECÁNICA / SOPORTE VENTILATORIO}

\section{MORTALIDAD EN NIÑOS Y ADOLESCENTES CON VENTILACIÓN MECÁNICA DOMICILIARIA: REVISIÓN SISTEMÁTI-} CA DE LA LITERATURA Y METANÁLISIS

Roberto Vera Uribe, Francisca Zarricueta , Paulina Martinez , Luis Vasconcello , Jordi Vilaró , Claudia Simerei Albertini, Rebeca Paiva , Rodrigo Torres Castro Programa de Doctorado en Ciencias de la Salud. Universitat Internacional de Catalunya. Barcelona, España.

Introducción: La tasa de niños que requieren ventilación mecánica domiciliaria (VMD) está creciendo rápidamente como consecuencia del desarrollo de las tecnologías sanitarias y el diagnóstico precoz de patologías graves. El traslado a sus hogares requiere un entrenamiento a los cuidadores y equipamiento para prevenir eventos fatales. Nuestro objetivo fue determinar la tasa de mortalidad en niños con VMD. Métodos: Realizamos una revisión sistemática de la literatura en 5 bases de datos desde enero de 2020 hasta agosto de 2021. Incluimos estudios que hubiesen evaluado la mortalidad en niños con VMD. Dos revisores independientes analizaron los resultados, extrajeron los datos, evaluaron la calidad de los artículos y sintetizaron la evidencia. El protocolo fue registrado en PROSPERO y seguimos las recomendaciones PRISMA. Para la evaluación de la calidad de los estudios usamos la escala NHBLI. Resultados: De un total de 6.200 resúmenes y títulos revisados se seleccionaron 30 artículos que representaron un total de 2949 niños. La mayoría de los estudios fueron cohortes retrospectivas (60\%) y fueron calificados de mala calidad. Los diagnósticos principales fueron enfermedad neuromuscular (43,6\%), enfermedad respiratoria $(22,2 \%$ ) y enfermedad del sistema nervioso central $(18,7 \%)$. Los artículos analizados en el meta-análisis fueron 21, los que reportaron 422 eventos fatales en un total de 2599 niños y adolescentes. La mortalidad total fue de 18 (15-22) \% (p<0,01, 12 77\%). Conclusión: En niños con VMD la mortalidad por eventos en el hogar fue de un $18 \%$. El diagnóstico principal fue de ENM.

\section{OTROS}

\section{NEUMONÍA NECROTIZANTE Y SUS COMPLICACIONES: EXPERIENCIA DE 3 AÑOS EN UN HOSPITAL PEDIÁTRICO}

Javier Cepeda Soto, Maria Luisa Espinoza Ovalle, Gerardo Torres Puebla, Ricardo Kogan Alterman

Hospital Exequiel González Cortés Santiago, Chile.

Introducción: La neumonía necrotizante es una complicación severa de la neumonía adquirida en la comunidad (NAC), caracterizada por una extensa destrucción y licuefacción del tejido pulmonar cuya incidencia ha aumentado progresivamente desde sus primeros reportes hace poco más de 2 décadas. Objetivos: El objetivo del presente estudio fue describir las características demográficas, clínicas, etiología, manejo y seguimiento de pacientes pediátricos tratados por neumonía necrotizante en un hospital pediátrico terciario. Materiales y métodos: Serie de casos retrospectiva. Muestreo por conveniencia de pacientes entre 1 mes y 18 años ingre- sados al Hospital Dr. Exequiel González Cortes entre marzo 2018 y julio 2021 con diagnóstico de Neumonía Necrotizante. Resultados: Se incluyeron 17 pacientes (65\% mujeres) correspondientes al $1,6 \%$ de todos los pacientes egresados por neumonía bacteriana. La mediana de edad fue 41 (RIC 15,5 - 88,5) meses. Las manifestaciones clínicas más frecuentes al ingreso fueron: fiebre $(94,1 \%)$, taquipnea y tos (ambos $82,4 \%$ ). La mediana de duración de la fiebre fue 12 (RIC 9,0 - 15,0) días. El agente etiológico fue identificado 35,3\% de los casos, siendo el más frecuente neumococo $(50 \%)$. La mediana de duración de la estadía hospitalaria fue 
24 (RIC 14,0 - 33,0) días y del tratamiento antibiótico 28 (RIC 21,0 - 31,0) días. La complicación respiratoria más frecuentemente asociada fue empiema pleural (65\%). El 11,7\% pacientes requirieron ingreso a oxigenación de membrana extracorpórea. Conclusión: La neumonía necrotizante es una complicación infrecuente aunque potencialmente severa de la NAC, incluso en pacientes previamente sanos. El manejo es conservador a excepción de aquellos asociados a empiema pleural.

\section{¿CIANOSIS EN PUERICULTURA, SUPC O BRUE DE ALTO RIESGO? ESTUDIO DESCRIPTIVO}

Rosa Silva Muñoz, Javier Cifuentes Recondo, Yorley González , Sergio Ambliado , Bianca Lobos , Marcia Henríquez , Rodrigo Lagos

Clínica Indisa Santiago, Chile.

Introducción: Existen variadas patologías, que tienen como síntoma principal cianosis y cese de respiración, sin síntomas que evidencien un cuadro claro. Entre ellas SUPC y BRUE, ambos coinciden en que generan en los tutores una experiencia aterradora, sin embargo, difieren ampliamente en el pronóstico, si para un BRUE la tasa de complicaciones y/o muerte es de aproximadamente 1 en 800 niños nacidos vivos, para SUPC es $27 \%$ de muerte y $24 \%$ de daño neurológico. Objetivos: Medir la frecuencia de ocurrencia de un episodio de BRUE, definir las características clínicas, resultado de la evaluación diagnóstica y riesgo de recurrencia. Materiales y métodos: El estudio es descriptivo, observacional, prospectivo, con componente analítico. RN cuyo parto fue atendido en Clínica Indisa y cumplan criterios de inclusión. Los criterios de hospitalización y estudio diagnóstico son los definidos según protocolo en uso. Además, encuesta telefónica a los 28 días de vida. Resultados n:3855 partos (84,19\%) fueron $\mathrm{RN}>34$ semanas, 145 (3,17\%; IC: 3-4\%) presentaron un episodio de BRUE, con una incidencia de 37,61 x1000RNV. 1 RN presentó 1 episodio de SUPC con paro cardiorrespiratorio (incidencia 0,26 x 1000 RNV). En $14(25,00 \% ; 65,56-88,41 \%)$ se logró objetivar un diagnóstico. 4 (3,08\%; IC:0,84-7,69\%) repitieron 1 evento de SUPC en sus casas, de ellos solo 1 se rehospitalizó. Conclusión: La gran mayoría de los eventos son BRUE, episodios de SUPC son infrecuentes. El protocolo aplicado permite llegar a diagnóstico en algunos casos, y tener una pauta eficaz de manejo. La tasa de recurrencia durante el periodo neonatal es baja.

\section{MALFORMACIONES CONGÉNITAS PULMONARES: UNA EXPERIENCIA DE 13 AÑOS EN UN HOSPITAL PEDIÁTRICO}

Shirley Sarmiento Brito, Selim Abara Elias, Ivan Mendoza Gutierrez, Daniel Rojo Vera, Leonardo Jara Montenegro, Maria José Henriquez, Francisca Gallegos Hospital el Carmen. Santiago, Chile.

Introducción: Las malformaciones congénitas pulmonares (MCP) es una anormalidad poco común, generalmente se presenta durante el período prenatal o primera infancia. En este estudio nuestro objetivo es describir los hallazgos clínicos, imagenológicos, anatomopatológicos y quirúrgicos de pacientes con MCP en nuestro centro entre 2007- 2021. Material y métodos: Revisamos 27 informes de resultados de anatomía patológica con diagnóstico de MCP en Hospital Exequiel González Cortés entre 2007-2021. En base a esto se realiza una revisión retrospectiva de fichas clínicas. Resultados: Población a estudio son 27 pacientes, 15 mujeres (55,5\%), edad media 3,4 años (0 - 13 años). Sospecha diagnóstica basada en diagnóstico prenatal $25,9 \%$, hallazgos radiológicos $14,8 \%$, neumonías a repetición $22,2 \%$ y SDR neonatal 3,7\%. Se realizó radiografía a todos, TAC pulmonar $44,4 \%$, AngioTac $22,2 \%$ y un $33,3 \%$ sin descripción. Mal- formación más diagnosticada fué MPCVA 59,3\% y tomando en cuenta la clasificación de Stocker la malformación tipo II es más frecuentemente encontrada $75 \%$. En segundo lugar, secuestro pulmonar $22 \%$, seguido de quistes broncogénicos 14,8\% (precarinal 1, subcarinal 2, no especificado 1), y enfisema lobar congénito 7,4\%. Mayor incidencia de diagnóstico anatomopatológico fue entre 2 y 5 años. Tratamiento quirúrgico en todos los pacientes con lobectomía de las zonas comprometidas y $18,5 \%$ presentaron complicaciones poscirugía (Atelectasia 1, Neumotórax 4, sólo uno con VMI). Se operaron 10 pacientes $\leq 1$ año de vida ( $37 \%$ ) (30\% al mes de vida). No se registró mortalidad. Conclusión: Se destaca el diagnóstico precoz y buena evolución de nuestros pacientes concordantes con la literatura.

\section{EFECTO DE LA FISIOTERAPIA RESPIRATORIA GUIADA POR AUSCULTACIÓN EN BRONQUIOLITIS AGUDA}

Nathalia Suarez Sanabria, Laura Ruiz Vélez, Alejandra Mercado Espinoza, Lorena Marquez Franco

Hospital Infantil Santa Ana. Medellín, Universidad CES Medellín, Colombia.

Introducción: La bronquiolitis aguda, es la infección respiratoria de la vía aérea inferior más común en menores de 2 años. A pesar de su alta incidencia y morbilidad existen pocas terapias efectivas para su tratamiento, el cual se basa en el manejo sintomático. Existe controversia sobre la efectividad de las técnicas de fisioterapia de tórax convencionales. El objetivo del estudió fue determinar el efecto de la fisioterapia respiratoria no convencional, guiada por auscultación en menores de 24 meses con bronquiolitis en el Hospital Infantil Santa Ana. Se realizó un estudio cuantitativo con un enfoque metodológico cuasi experimental: pre y post intervención. El tamaño muestral fue de 122 pacientes con clasificación de obstrucción bronquial leve o moderado según la escala de Wang, a quienes se intervino con técnicas de fisioterapia respiratoria guiada por auscultación, según la corriente descrita por Guy Postiaux. Se caracterizó la población y se determinó su estado clínico inicial. Se evaluó el cambio en la escala de Wang post intervención, a las 24 y 48 horas respectivamente. Se utilizaron las pruebas U de Mann Whitney, Kruskal Wallis y Spearman relacionando variables categóricas y la variable resultado principal. Se hallaron cambios estadísticamente significativos en el nivel de obstrucción bronquial posterior a la intervención de fisioterapia a las 24 y a las 48 horas, siendo más significativo en esta última medición ( $p=0.04$ Vs $p=0,00$ ). Las técnicas de fisioterapia respiratoria no convencionales tienen un efecto positivo para la disminución de la obstrucción bronquial en los niños con Bronquiolitis aguda. 


\section{Sociedad Chilena de Neumología Pediátrica

Las reuniones mensuales se realizan en forma remota a las $19 \mathrm{~h}$. Se puede acceder desde la página web de la Sociedad Chilena de Neumología Pediátrica: https:// sochinep. com/site/index.php. Se requiere de la inscripción desde una semana antes de la fecha de cada reunión. De esta forma recibirá en su correo la clave de acceso el día de la misma.

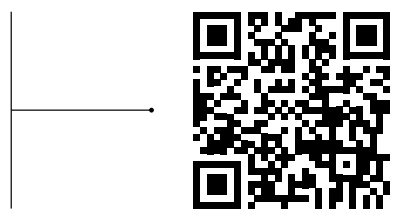

Próximas reuniones

\begin{tabular}{|c|c|c|}
\hline AÑO 2021 & DÍA & CENTRO \\
\hline MARZO & 4 & Hospital Osorno \\
\hline ABRIL & 1 & H. Luis Calvo Mackenna \\
\hline MAYO & 3 & Hospital Sótero del Río \\
\hline JULIO & 1 & Hospital San Juan de Dios \\
\hline ACOSTO & 5 & Hospital San Borja Arriarán \\
\hline SEPTIEMBRE & 2 & Clínica INDISA \\
\hline OCTUBRE & 7 & Hospital Roberto del Río \\
\hline NOVIEMBRE & 4 & Hospital de Ovalle \\
\hline DICIEMBRE & 2 & Hospitales Van Buren-Fricke \\
\hline
\end{tabular}

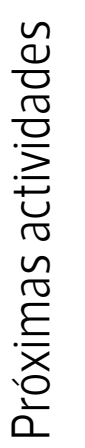

XVI JORNADAS DE ACTUALIZACIÓN EN ENFERMEDADES RESPIRATORIAS INFANTILES SOCHINEP

Fecha: 13 y 15 de mayo 2021

Modalidad Online

XVII CONGRESO ANUAL SOCHINEP

Fecha: 19 al 23 de octubre 2021

Modalidad Online

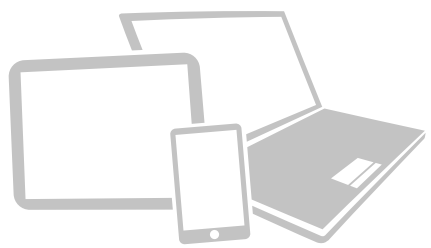




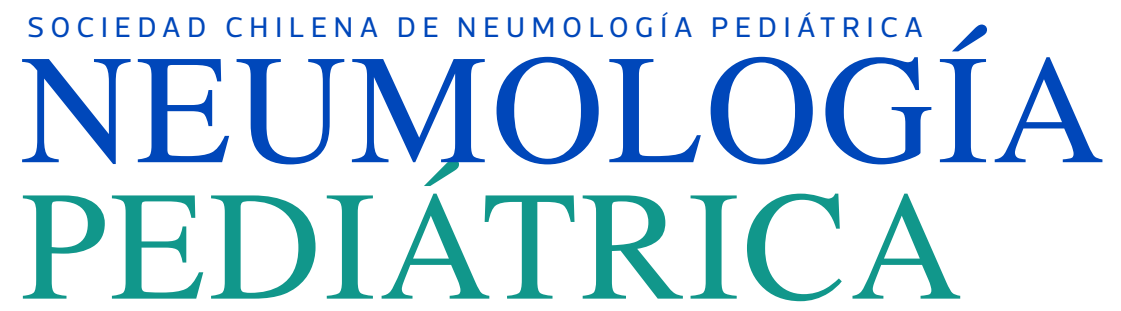

Órgano oficial de difusión de la

Sociedad Chilena de

Neumología Pediátrica (SOCHINEP)

y de la Sociedad Latinoamericana de

Neumología Pediátrica (SOLANEP)

La Revista Chilena de Neumología Pediátrica es el órgano oficial de la Sociedad Chilena de Neumología Pediátrica (SOCHINEP) y de la Sociedad Latinoamericana de Neumología Pediátrica (SOLANEP), exclusivamente dedicada a la salud respiratoria infantil.
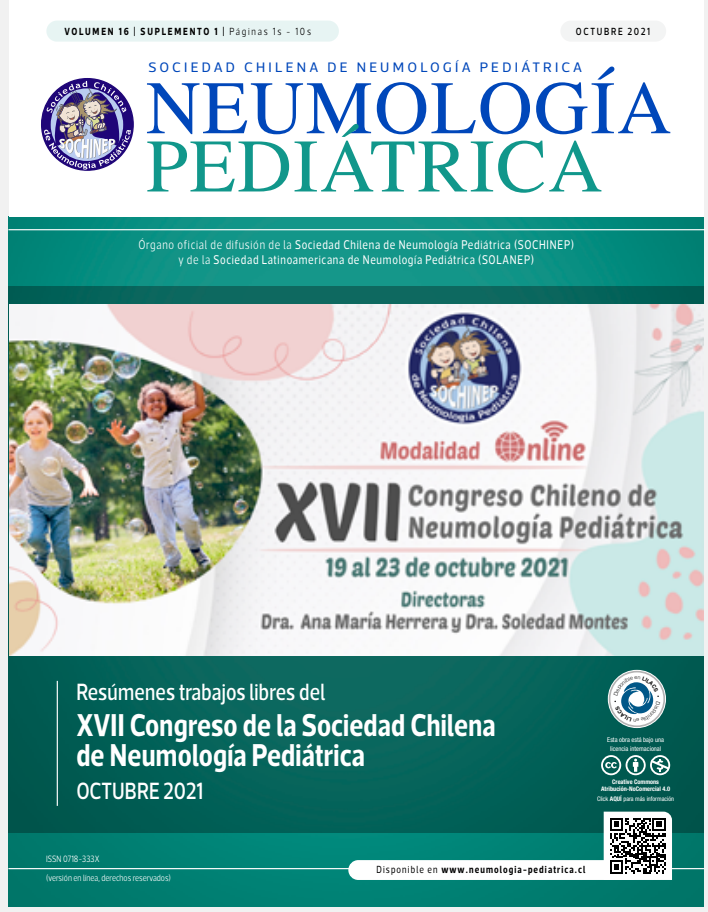

Es de acceso abierto, disponible en las páginas www.neumologiapediatrica.cl y www.savalnet.cl (revistas digitales). No exige cobros a los autores por concepto de envío, edición o publicación de los artículos.

Su misión es difundir conceptos actuales, promover la investigación y discusión científica a travéz de la publicación de artículos de revisión y actualización, casos clínicos, series de casos y artículos de investigación relacionados con la salud respiratoria infantil y del adolescente, que no se hayan publicado en otras revistas. El Comité Editorial revisa cuidadosamente los trabajos enviados y los trabajos originales y casos y serie de casoso clínicos se somenten a revisión por pares abierta.

Está dirigida a: médicos generales, familiares, pediatras, subespecialistas en enfermedades respiratorias, kinesiólogos, enfermeras y estudiantes.

Indizada en el directorio Latindex y bases de revistas científicas LILACS y BIREME. Su impresión es exclusivamente digital desde el año 2014 y tiene periodicidad trimestral.

Oficina comercial: Miguel Claro 195, oficina 101, Providencia, Santiago, Chile.

Editorial: Laboratorio SAVAL. Av Pdte Eduardo Frei Montalva 4.600, Renca, Santiago.

Está prohibida la reproducción parcial o total de la revista para propósitos comerciales.

Esta obra está bajo una licencia internacional Creative Commons Atribución-NoComercial 4.0.

\section{() (1) $\$$}


Las directrices para autores están basadas en:

Uniform requirements for manuscripts submitted to biomedical journals. Ann intern med 1979; 90: 95-9

International Committee of Medical Journal Editors (ICMJE). Uniform requirements for manuscripts submitted to biomedical journals. http://Www.icmje.

org/recommendations

Características generales de los manuscritos

- El margen de la página debe ser 2,5 cm en los 4 bordes.

- $\quad$ Letra Arial o Times New Roman, tamaño 12, espaciado 1,5.

- Al final del manuscrito debe señalar conflictos de intereses.

- Luego puede expresar agradecimientos a personas e instituciones que hubiesen hecho contribuciones sustantivas a la revisión que no cumplan con los criterios de autoría.

- Si se publican fotografías de personas, estas no deben ser identificables; debe anexarse el consentimiento informado y explicitarlo en el manuscrito.

- Debe enviar copia Declaración de Responsabilidad vía correo electrónico a contacto@neumología-pediatrica.cl

El manuscrito debe contener (en el siguiente orden):

- Título: en español (o portugués) y en inglés.

- $\quad$ Autores: abreviatura de la profesión, primer nombre y primer apellido..

- Grado académico y/o afiliación institucional de los autores, marcando entre paréntesis número identificador.

- $\quad$ Autor para correspondencia: lugar de trabajo, dirección, teléfono y correo electrónico.

- $\quad$ Resumen y palabras clave en inglés (Abstract, Key words) (máximo 250 palabras).

- Resumen y palabras clave en español o portugués según autor (máximo 250 palabras) - Las palabras clave en español (o portugués) e inglés (3 a 5), se deben referir a términos MeSH (https://meshb.nlm.nih.gov/search)

- Manuscrito (varía su estructura según el tipo específico del manuscrito).

- Tablas y Figuras (estas últimas en JEPG, mínima resolución 300 dpi).

- Declaración de conflicto de intereses.

- Agradecimientos.

- Referencias bibliográficas.

\section{TIPOS ESPECÍFICOS DE MANUSCRITOS:}

\section{ARTÍCULOS ORIGINALES DE INVESTIGACIÓN}

- Este tipo de artículo revela resultados de investigaciones clínicas o básicas. Los resultados deben ser presentados de tal forma que puedan ser reproducidos y recalculados por otros autores.

- $\quad$ La presentación de un artículo implica que el trabajo descrito no ha sido publicado previamente (excepto en la forma de un resumen o presentación en congreso, o casos especiales con la debida autorización del editor correspondiente) y que no va a ser publicado en otro lugar de la misma forma, en español en cualquier otro idioma, sin el consentimiento por escrito del editor.

- En caso de realizar investigación en seres humanos, se debe indicar si los procedimientos seguidos fueron aprobados por comité de ética de la institución donde se llevó a cabo el estudio. Lo mismo en relación a estudios realizados con animales de experimentación.

- L Los autores deben mencionar en la sección de métodos si se obtuvo consentimiento y/o asentimiento informado por parte de los sujetos que participaron en el estudio.

- No debe exceder las 3.000 palabras, sin considerar las referencias y resúmenes y un máximo de 7 figuras/tablas. No colocar más de 50 referencias bibliográficas.

\section{ESTRUCTURA}

- Introducción: Exprese claramente el propósito del artículo. No revise extensamente el tema y cite solamente las referencias bibliográficas necesarias. En esta sección se redacta el objetivo del trabajo.

- $\quad$ Pacientes y Método: Se debe describir los métodos, mecanismos y procedimientos con suficiente detalle como para permitir que otros puedan reproducir los resultados. Cuando se trata de métodos establecidos y de uso frecuente limítese a nombrarlos y cite las referencias respectivas. Cuando los métodos ya han sido publicados pero no son bien conocidos, proporcione las referencias y agregue una breve descripción. Cuando los métodos son nuevos o aplicó modificaciones a métodos establecidos, descríbalos con precisión, justifique su empleo y enuncie sus limitaciones. Si se utilizaron equipos médicos debe detallarse marca, año fabricación, lugar de origen. Los métodos estadísticos deben ser precisos y completos. Deben permitir verificar los resultados presentados.

- $\quad$ Resultados: Presentarlos de forma concisa y precisa. Iniciar con descripción del (los) grupo(s) de estudio (Tabla 1). Incluir el tamaño de la muestra de cada grupo de datos, valores de significancia, intervalos de confianza, etc, según corresponda. Los datos se pueden mostrar en tablas o figuras, pero no simultáneamente en ambas. No repita en el texto la descripción de todos los datos que se presentan en una tabla 0 
figura, destaque o resuma en el texto sólo las observaciones importantes. No mezcle la presentación de los resultados con su discusión.

- $\quad$ Discusión: No repita los datos que aparecen en los resultados. El primer párrafo debe describir los hallazgos más importantes del estudio. Comentar las implicancias de los hallazgos y sus limitaciones. Relacione las observaciones de su estudio con otros resultados de trabajos publicados, identificándolos mediante las citas bibliográficas respectivas. Plantee nuevos interrogantes para investigación futura.

- Conclusiones: Esta sección debe ser distinta de la discusión. Debe ser concisa y debe precisar los hallazgos clave de la investigación y sus implicancias clínicas. Conecte sus conclusiones con los objetivos del estudio que señaló en la introducción, pero evite proponer conclusiones que no están sólidamente respaldadas por sus hallazgos, así como apoyarse en otros trabajos que aún no están terminados.

- $\quad$ Referencias bibliográficas: Deben ser numeradas consecutivamente (entre paréntesis) en el orden en que son citadas por primera vez en el texto, al final de cada frase o párrafo en que se las alude. Si se trata de trabajos enviados a publicación pero no oficialmente aceptados, refiéralo en el texto como "observaciones no publicadas", entre paréntesis. El formato debe ser Vancouver. Los autores son responsables de la exactitud de las referencias. El máximo de referencias permitido es de 30. En los artículos de revisión (actualización) el número de referencias puede ser mayor a 30 .

Agregar DOI (Identificador Digital Objetivo), identificador Pubmed y pii de estar disponible. Se sugiere el uso de un gestor bibliográfico (Mendeley).

\section{EJEMPLOS DE CITACIONES}

- Referencias de revistas: Apellidos seguido de las iniciales de los nombres de los autores (si el número de autores es mayor de 6, coloque los tres primeros autores seguidos de la frase "et al"), título del artículo, título abreviado de la revista (según Journals Database y BREV), año, volumen y página inicial y final.

Ejemplo: Zachs MS. The physiology of forced expiration. Paediatr Respir Rev 2000; 36-39

- Referencias de textos: Apellidos, iniciales del nombre del autor, título del texto, editorial, ciudad, estado, país y año de la publicación. Ejemplo: West J B. Pulmonary Physiology. The essentials. Williams and Wilkins Co. Baltimore, Md, USA, 1978.

- Referencias de capítulos en textos: Apellidos e inicial del nombre del o los autores del capítulo. Título del capítulo; y, después de la preposición "en", apellido del editor, título del libro (edición si es otra de la primera), ciudad, casa editorial, año y páginas. Ejemplo: Levitsky M. Mechanics of Breathing. In Pulmonary Physiology. McGraw-Hill Companies, Inc, 7th Edition, USA, 2007, pag 11-53

- $\quad$ Referencias de páginas Web: Título de la información que se quiere citar [internet], país de donde proviene la información: institución o entidad a la que se atribuye autoría; c+año (que se refiere al año en que la información fue escrita) y luego la fecha en que los autores están citando y finalmente la página web

Ejemplos: Boletín Vigilancia de laboratorio: Resultados confirmación de infección por VIH en Chile, 2010 - 2015. [Internet] Chile: Instituto de Salud Pública; c2016 [cited 2020 Mar 09]. Available from: http:// www.ispch.cl/sites/default/files/BoletinVIH-15112017A.pdf American Medical Association [Internet]. Chicago: The Association; c1995-2016 [cited 2016 Dec 27]. Office of International Medicine; [about 2 screens]. Available from: https://www.ama-assn.org/about/office-international-medicine

- Referencia de artículo de revista en internet: Apellidos seguido de las iniciales de los nombres de los autores, título del artículo, título abreviado de la revista [Internet] año, y luego la fecha en que los autores están citando volumen (número).... ):[about 1 p.].. y disponible en. Ejemplo: Abood S. Quality improvement initiative in nursing homes: the ANA acts in an advisory role. Am J Nurs [Internet]. 2002 Jun [cited 2002 Aug 12];102(6):[about 1p.]. Available from: https:/ / ovidsp.tx.ovid.com/

Para más detalles referirse a los "Requisitos de uniformidad para manuscritos enviados a revistas biomédicas ", http://www.nlm.nih.gov/bsd/uniform requirements.html o http://www.fisterra.com/herramientas/recursos/vancouver

- Tablas y figuras: Deben incluirse intercaladas en el texto, según orden de mención en el mismo. Use notas aclaratorias para todas las abreviaturas no standard. Para las notas al pie utilizar los símbolos *, \#, S, etc. Máximo 7 Tablas (en total con Figuras). Si las ilustraciones son tomadas de fuentes publicadas, debe expresarse el permiso del autor y de la revista por escrito, y mencionar la publicación utilizada. Cada tabla o figura debe tener un texto explicativo que permita entenderla, sin necesidad de recurrir al texto.

- $\quad$ Figuras: si están en formato JEPG su resolución debe ser mínimo 300 dpi y su tamaño media carta.

\section{CASOS CLÍNICOS}

Su publicación tiene como objetivo mostrar casos o series de casos que presenten algún aspecto de originalidad, como por ejemplo, corresponder a una patología poco frecuente en el lugar donde se desarrolla, presentación clínica diferente a la descrita, técnicas diagnósticas o terapéuticas novedosas, aumento de la prevalencia habitual de una patología, etc.

- Reporte de 1 caso. El texto no debe exceder las 1.000 palabras, sin incluir resúmenes, referencias, ni texto de figuras y/o tablas. Reporte de 20 más casos. El texto no debe exceder las 2.000 palabras, sin incluir resúmenes, referencias, ni texto de figuras y/o tablas.

- No más de 5 Figuras/Tablas.

- Entre 7 a 20 referencias bibliográficas.

- Estructura: Caso Clínico detallado (en reemplazando las secciones "Paciente y Método" y "Resultados"). 


\section{ARTÍCULOS DE REVISIÓN}

Manuscritos encargados por el comité editorial de la revista a un profesional especialista en un tema. Los documentos presentados para su publicación deben ser escritos de forma concisa y clara.

- No debe exceder las 3.000 palabras, sin considerar las referencias y resúmenes.

- No colocar más de 7 Figuras/tablas.

- Pueden colocarse más de 30 Referencias bibliográficas.

\section{EDITORIALES}

Escritos breves, que relatan comentarios sobre un tema científico, de actualidad, política editorial, o de interés general, o comentario sobre los artículos publicados en el mismo ejemplar. Se le solicita al comité editorial de la revista a un autor o grupo de autores especialistas en un tema.

- No debe exceder las 1.000 palabras.

- No colocar más de 10 referencias bibliográficas.

- Sin resumen, ni cuadros o figuras.

- Puede o no tener referencias. 
SOCIEDAD CHILENA DE NEUMOLOGÍA PEDIÁTRICA

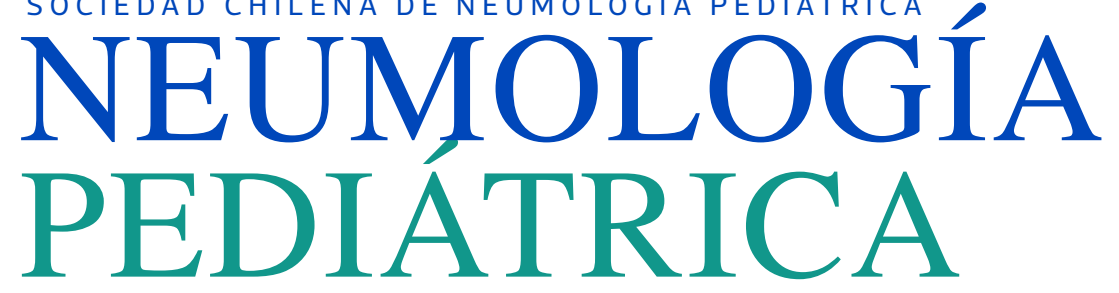

Órgano oficial de difusión de la

Sociedad Chilena de

Neumología Pediátrica (SOCHINEP)

y de la Sociedad Latinoamericana de

Neumología Pediátrica (SOLANEP)

\section{DECLARACIÓN DE RESPONSABILIDAD}

\section{Título del manuscrito:}

1. Certifico que he contribuido directamente al contenido intelectual del manuscrito, a la búsqueda y análisis de sus datos, por lo cual me hago públicamente responsable de él.

2. El artículo es inédito. No ha sido enviado a otra revista, ni lo será en el futuro.

3. Marque la alternativa que corresponde:

El trabajo no incluye material gráfico tomado de otras publicaciones.

El trabajo incluye material gráfico tomado de otras publicaciones. Adjunto copia de la autorización del autor original.

Nombre del autor:

Firma:

Teléfono(s):

Correo electrónico:

Fecha: 


\section{Distintas opciones para el manejo de CUADROS ALÉRGICOS con calidad SAVAL}

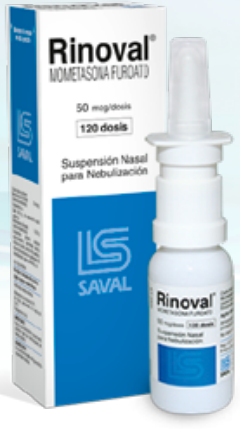

Rinoval ${ }^{\oplus}$ MOMETASONA FUROATO Envase nebulizador con 120 dosis, 50 mcg por dosis

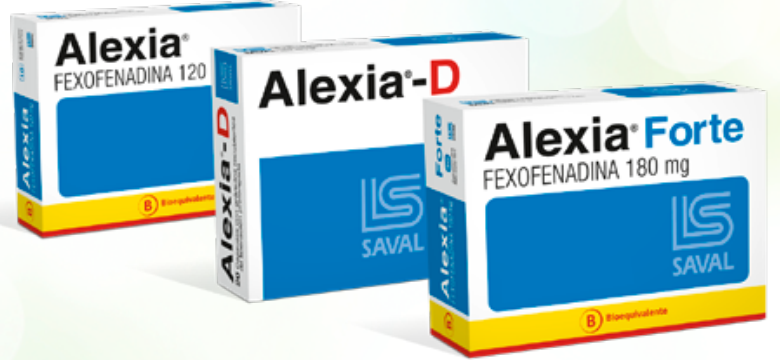

Alexia ${ }^{\circledR}$ FEXOFENADINA

Envases de $120 \mathrm{mg}$ con 10 y 30 comprimidos recubiertos y ranurados

Alexia ${ }^{\circledR}$ D FEXOFENADINA - PSEUDOEFEDRINA

Envases de $60 \mathrm{mg}$ de Fexofenadina / $120 \mathrm{mg}$ de Pseudoefedrina con 10 y 20 cápsulas

Alexia ${ }^{\circledR}$ Forte FEXOFENADINA

Envases de $180 \mathrm{mg}$ con 10 y 30 comprimidos recubiertos y ranurados

Zival $^{\circledR}$ LEVOCETIRIZINA DICLORHIDRATO Envase con 40 comprimidos recubiertos de $5 \mathrm{mg}$ Envase con $120 \mathrm{ml}$ de jarabe de $2,5 \mathrm{mg} / 5 \mathrm{ml}$ Envase con $20 \mathrm{ml}$ de solución para gotas $5 \mathrm{mg} / \mathrm{ml}$

Zival ${ }^{\circledR}$ Forte LEVOCETIRIIINA DICLORHIDRATO Envase con $120 \mathrm{ml}$ de jarabe de $5 \mathrm{mg} / 5 \mathrm{ml}$

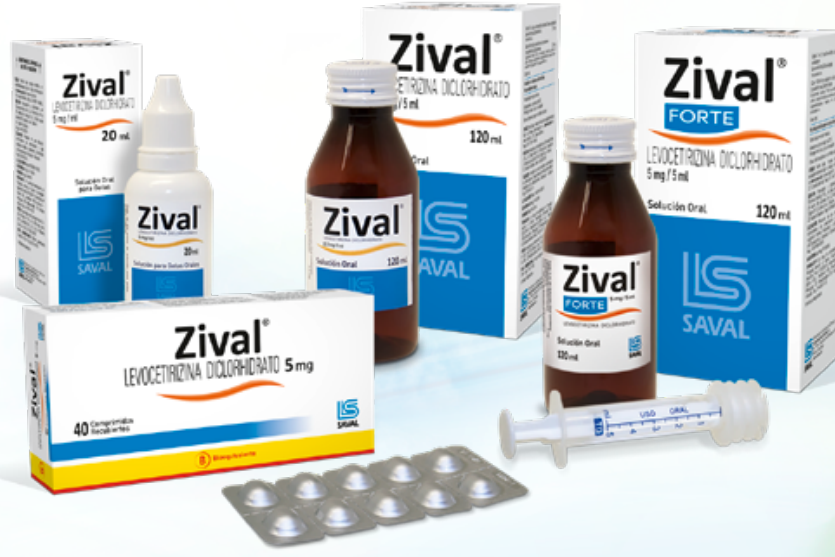

Lukanex ${ }^{\circledR}$ MONTELUKAST
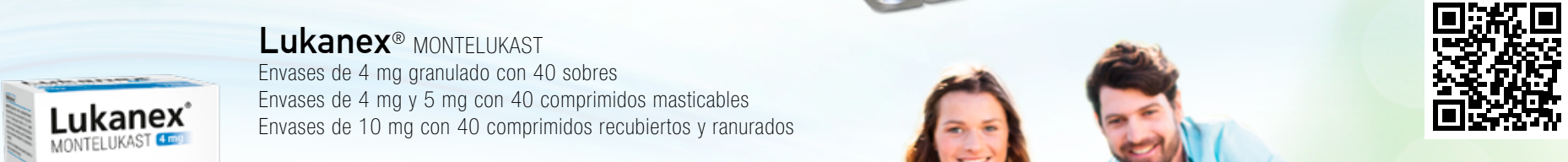

1. $40=$
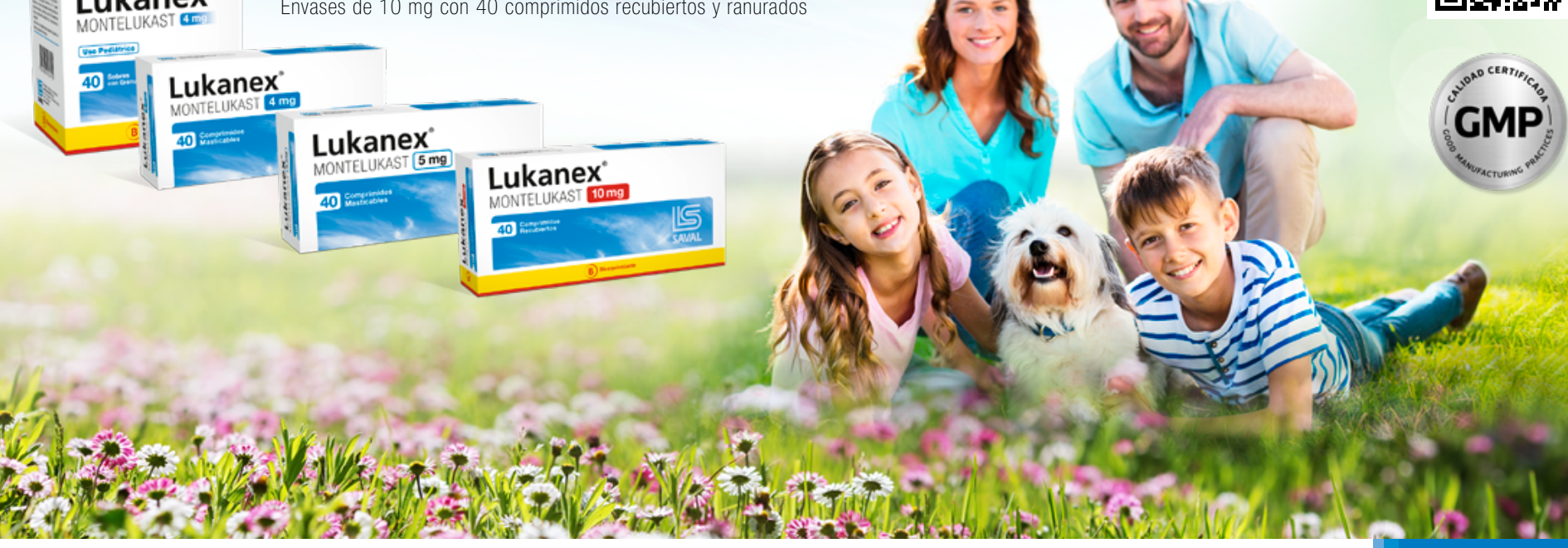


\section{Calidad farmacéutica más cerca de sus pacientes}

\section{Amoval}

AMOXICILINA / SAVAL

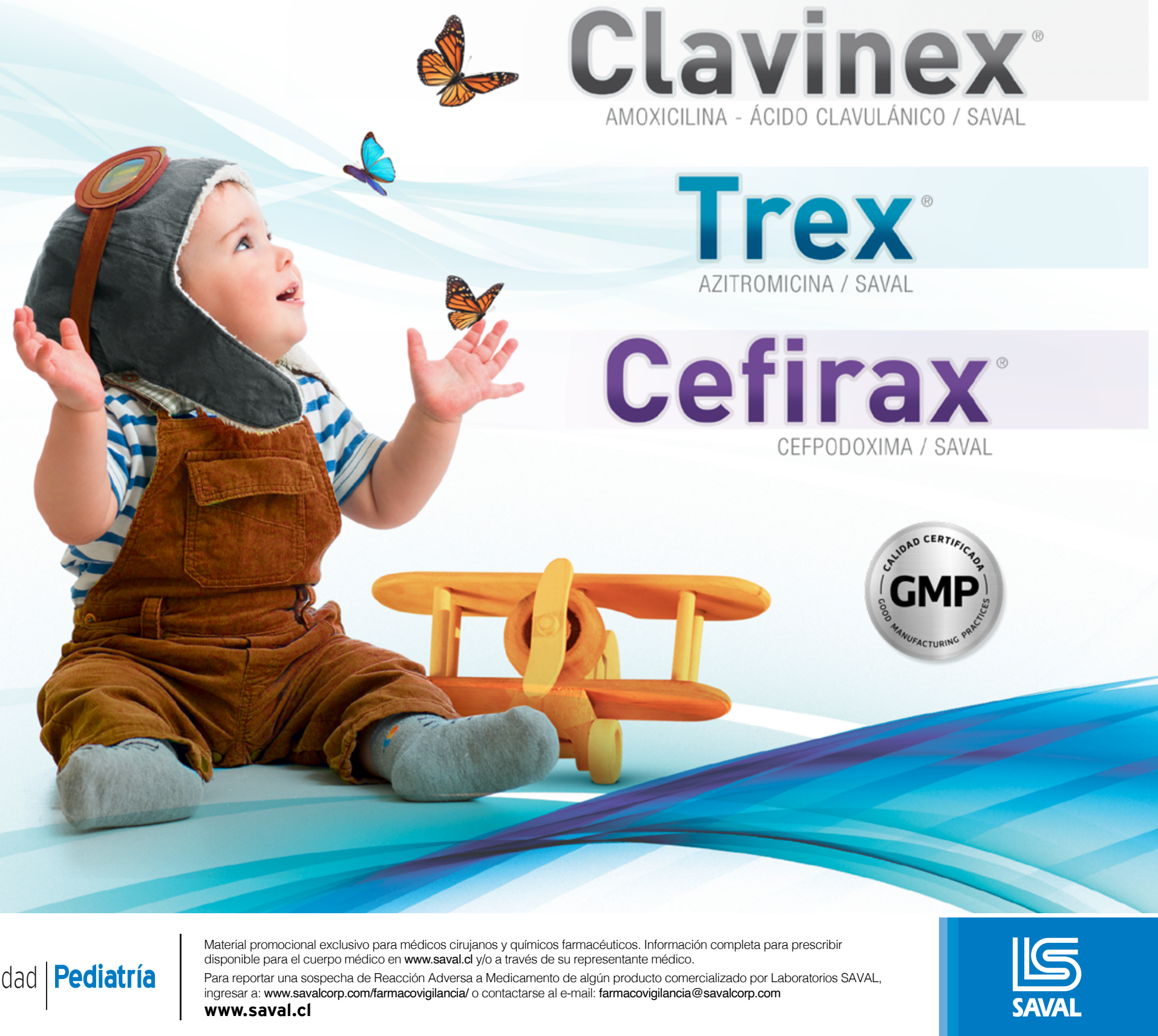




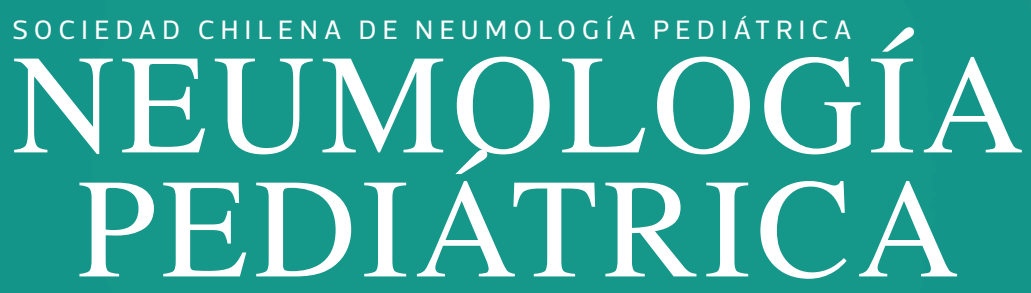

Órgano oficial de difusión de la Sociedad Chilena de Neumología Pediátrica (SOCHINEP) y de la Sociedad Latinoamericana de Neumología Pediátrica (SOLANEP) 